Article

\title{
Trophic Patterns of Bighead Carp and Silver Carp Follow the Seasonality of Resource Availability
}

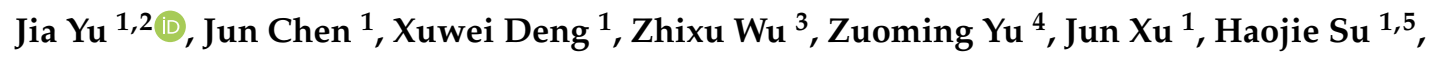 \\ Jiarui Liu ${ }^{1}$, Li Wang ${ }^{1}$, Yao $\mathrm{Wu}^{1}$ and Ping Xie ${ }^{1,2, *}$ \\ 1 Donghu Experimental Station of Lake Ecosystems, State Key Laboratory of Freshwater Ecology and \\ Biotechnology, Institute of Hydrobiology, Chinese Academy of Sciences, Wuhan 430072, China \\ 2 College of Fisheries, Huazhong Agricultural University, Wuhan 430070, China \\ 3 Chun'an Branch, Hangzhou Ecological Environment Bureau, Hangzhou 311700, China \\ 4 Center of Science Research, Hangzhou Institute of Environmental Sciences, Hangzhou 310000, China \\ 5 Department of Ecology, College of Urban and Environmental Sciences, Peking University, \\ Beijing 100871, China \\ * Correspondence: xieping@ihb.ac.cn; Tel.: +86-27-68780622
}

Received: 22 May 2019; Accepted: 8 July 2019; Published: 12 July 2019

\begin{abstract}
The influence of seasonality of the aquatic environment on food web has been notoriously understudied in empirical ecology. In this study, we focus on seasonal changes in one key attribute of a food web, the trophic level. We determine whether seasonal variations of fish trophic levels could be indicated by the change in food resources. Silver carp (Hypophthalmichthys molitrix) and bighead carp (H. nobilis) were used to explore the responses of trophic levels of the filter-feeding fish to seasonal variations of food resources. Combined stable isotopic analysis and dietary analysis revealed that filter-feeding fish tended to have a higher trophic level in spring (May) and autumn (September and October). This may result from the abundant density of food resources (zooplankton and phytoplankton) and fish flexible foraging strategy, as we predicted that the trophic level follows the seasonality of food availability. Pearson' correlation analysis and a structural equation model showed that seasonal variation of total phosphorus and water temperature could indirectly affect trophic levels of silver carp and bighead carp by mediating the abundance of phytoplankton and zooplankton directly and indirectly along the food chain. According to these findings, the seasonal variation of food resources could be an important indicator of the temporal dynamics of the food web trophic pattern in freshwater ecosystems.
\end{abstract}

Keywords: trophic level; trophic niche width; seasonal variations; stable isotopic values; flexible foraging strategy

\section{Introduction}

A freshwater ecosystem is characterized by seasonal variations in light and water temperature which influence resource availability for organisms. Despite early recognition that seasonal variations can influence fish communities [1], the consequences of seasonality for the change of the aquatic food web structure remain poorly documented. It is increasingly investigated how seasonal variations in the abiotic environment influence the trophic levels of fish [2,3].

Existing spatial food web theories can provide some references for studies on temporal food webs $[4,5]$. For instance, flexible foraging strategy, which means consumers could change species proportion of food resources, could promote food web stability by tracking accessible or abundant food resource or weakening predation intensity for resource shortage [6,7]. Although bighead and silver carps utilize planktonic resources (phytoplankton and zooplankton), proportion contribution 
of food resources could be flexible due to the abundance of food resource [8]. Previous studies have shown that the trophic level of the same fish species varies across ecosystems [9] due to the different distribution [10,11] and relative availability of food resources [12]. Many of these studies implicitly assume that the trophic level of a consumer within a given system remains static over time. However, emerging evidence indicates that consumer trophic patterns can change with season $[2,13,14]$ and on an interannual basis [15], including freshwater fish [2], stream invertebrates [16], birds [17], and desert mammals [18].

Algal bloom in water bodies leads to the change of food composition of fish which in turn may change the food web structure [2]. Filter-feeding fish have been extensively applied to regulate plankton abundance and restore lake water $[19,20]$. However, the rapid increase of filter-feeding fish and strong top-down control have prominently affected the structure of the food web [21] and are likely to lead to consumer resource stability reduction [22]. Therefore, it is particularly important to understand the role of filter-feeding fish in the aquatic food web. Stable isotopes have been applied extensively to construct aquatic food webs, which can reveal the temporal variation in fish trophic levels and estimate the contribution of food resources to consumers [12,23,24]. In this study, we explored how trophic levels of the filter-feeding fish change with seasonal variations in the resource abundance, which is of great significance for the understanding of the temporal food webs in the aquatic ecosystem.

Filter-feeding fishes, such as silver carp (Hypophthalmichthys molitrix) and bighead carp (H. nobilis), are widely distributed and highly productive in lakes. Filter-feeding fish consuming plankton is a short and clear food chain, which is highly connected with water environments through biological and abiotic interactions [25]. Therefore, in this study, silver carp and bighead carp are used to explore the response of filter-feeding fish trophic levels to seasonal variation of food resources. Zhou et al. (2009) found that the stable carbon and nitrogen isotopic values of two carps (silver carp and bighead carp) and their food sources showed obvious seasonal variations. After that, McMeans et al. (2019) discovered that fish trophic levels showed dramatic seasonal variations. Previous studies have shown that the water conditions and the availability of food sources could affect the trophic level of fish and the structure of food webs [12,23]. However, the seasonal relationship between trophic levels of fish and food resources is largely unknown. We hypothesized that (i) trophic levels of the filter-feeding fishes are indirectly influenced by seasonal fluctuations of nutrient and temperature, which is mediated by controlling the resource availability (e.g., abundance of phytoplankton and zooplankton) and (ii) Trophic levels of the filter-feeding fish are affected by its flexible foraging strategy and dietary variations. This study can indicate the trophic levels of fish through seasonal variations of water environments, which can well reflect the dynamics of the complex temporal food web, and is of great significance to the management of aquatic ecosystem.

\section{Materials and Methods}

\subsection{Study Area}

Lake Qiandao is an artificial dam lake located in the upstream of Qiantang River (Figure 1). Lake Qiandao is a key nationally-protected drinking water source in the Yangtze River, China [26]. The lake watershed covers an area of $1.17 \times 10^{4} \mathrm{~km}^{2}$ [27]. The mean depth is $34 \mathrm{~m}$ (maximum is 108), surface area is $580 \mathrm{~km}^{2}$, and the water storage is $17.84 \times 10^{9} \mathrm{~m}^{3}$. Owing to the development of agriculture and tourism, as well as a rapid increase of the anthropogenic effects, the water environment is facing severe challenges in Lake Qiandao [26]. In previous studies, nutrient removal by floating aquatic macrophytes [28] and submerged macrophytes [29] was used for water purification. However, Lake Qiandao is so deep that aquatic macrophytes could not live there. Instead, silver carp and bighead carp were the major commercial fish species utilized to prevent algal blooms to improve drinking water quality [30]. Here, we use Qiandao Lake as a model system to investigate the response of filter-feeding fish trophic levels to the seasonal variations in food resources. 


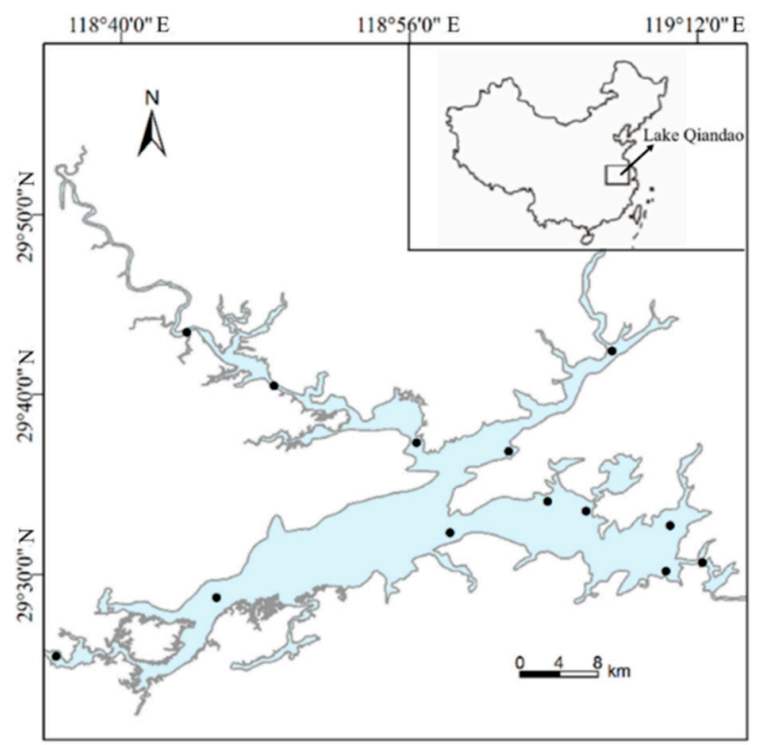

Figure 1. Map of Lake Qiandao in southern China.

\subsection{Sample Processing and Treatment}

The sampling procedure was carried out monthly from January to December in 2017. Thirteen sampling sites were set in Lake Qiandao (Figure 1). Water samples were collected from the surface, middle and bottom layers using a $5 \mathrm{~L}$ Schindler sampler (Wuhan, China) and mixed for total nitrogen (TN) and total phosphorus (TP) determination. Water temperature $(\mathrm{T})$ was measured by the multiparameter water quality meter YSI Pro Plus (Yellow Springs, OH, USA) at $0.5 \mathrm{~m}$ below the water surface in situ. Total nitrogen and total phosphorus were measured in the laboratory within $24 \mathrm{~h} \mathrm{[31].}$ With regard to crustacean zooplankton, $10 \mathrm{~L}$ water samples were sieved through 64 um plankton nets and preserved with $5 \%$ formalin for further identification. Then, a $1 \mathrm{~L}$ water sample for phytoplankton identification was preserved in acetic Lugol's solution and concentrated to $50 \mathrm{~mL}$ after sedimentation for $48 \mathrm{~h}$.

Samples for stable isotopic analyses were collected monthly. Filter-feeding fish samples were randomly collected by the Hangzhou Qiandao Lake Development Group CO. LTD. Generally, eight individuals of each species (silver carp and bighead carp) were utilized monthly. Dorsal muscle tissues of the fish were rinsed with distilled water and kept in a $-80^{\circ} \mathrm{C}$ refrigerator. Foregut contents were collected immediately and fixed in Lugol's iodine for a few minutes and then preserved with $10 \%$ formaldehyde solution for further identification. Foregut contents [14] and gill raker filtrates [32] are two methods for microscopic identification of diet assessment, but the foregut content is used in this study as it is more general method and has been applied by our research team consistently $[14,19,20,33]$. The phytoplankton for stable isotopic analyses was collected from filter lake water samples on glass fiber filters (Waterman GF/C, New York, NY, USA), and we removed the zooplankton and particulates under a microscope, and then collected these on glass fiber filters (Waterman GF/C) and rinsed them with $0.01 \mathrm{~N} \mathrm{HC1}$ and distilled water [34]. The zooplankton samples were collected including three processes: (i) filtering water samples through a plankton net with a 64um mesh size to get most of the zooplankton, (ii) removing the large-sized algal community under a microscope and (iii) collection on glass fiber filters (Waterman GF/C), followed by rinsing with $0.01 \mathrm{~N} \mathrm{HC1}$ and distilled water [2]. All samples for stable isotopic analyses were dried to a constant weight in an oven at $60^{\circ} \mathrm{C}$ [23]. Samples were ground into homogeneous powder and preserved in desiccators for subsequent analyses [35].

\subsection{Stable Isotope Analyses}

Stable carbon and nitrogen isotope values were analyzed with a Delta Plus (Finnigan, Bremen, Germany) continuous-flow isotope ratio mass spectrometer (CF-IRMS) directly coupled to a NA2500 
elemental analyzer (Carlo Erba Reagenti, Milan, Italy). Stable isotope ratios were expressed in delta $(\delta)$ notation in parts per thousand (\%o) deviation from the international standards, according to the following equation: $\delta X(\%)=\left(\left(R_{\text {sample }} / R_{\text {standard }}\right)-1\right) \times 1000$, where $X$ is the corresponding ratio to ${ }^{15} \mathrm{~N} /{ }^{14} \mathrm{~N}$ or ${ }^{13} \mathrm{C} /{ }^{12} \mathrm{C}$, R is ${ }^{15} \mathrm{~N}$ or ${ }^{13} \mathrm{C}$, and $\delta$ means the measure of heavy to light isotope in the sample. Two standards were run after every 10 samples to correct for instrumental drift during analysis. The deviations in the analysis of $\delta^{13} \mathrm{C}$ and $\delta^{15} \mathrm{~N}$ replicates were both within $0.3 \%$ [35].

\subsection{Trophic Level Estimates and Trophic Niche Width}

The zooplankton were used to estimate the trophic levels of the filter-feeding fishes, which is a more accurate parameter than primary productivity to calculate the trophic level $[23,35]$. The trophic levels of fish were calculated month by month.

Trophic level was calculated as follows:

$$
\text { Trophic level }=\lambda+\left(\delta^{15} \mathrm{~N}_{\text {fish }}-\left(\delta^{15} \mathrm{~N}_{\text {baseline }}\right)\right) / 3.4 \% \text {, }
$$

where $3.4 \%$ is generally an empirical value per trophic level enrichment of $\delta^{15} \mathrm{~N}$ (Post 2002). $\lambda=2$, which is used for primary consumers, is the baseline. $\delta^{15} \mathrm{~N}_{\text {fish }}$ and $\delta^{15} \mathrm{~N}_{\text {baseline }}$ represent the mean $\delta^{15} \mathrm{~N}$ of the fish and the zooplankton, respectively.

Standard ellipse area (SEA) was used to evaluate the isotopic niche width of bighead carp and silver carp, which reveals the core niche area. SEA is calculated based on the $\delta^{13} \mathrm{C}$ and $\delta^{15} \mathrm{~N}$ value and contains about $40 \%$ data. We used the corrected standard ellipse area (SEAc) as a measure of the trophic niche width. Furthermore, SEAc can be used as a quantitative measure of dietary similarity among populations because it can calculate the degree of isotopic niche overlap. All metrics were calculated using the R statistical computing package "siar" [36].

\subsection{Structural Equation Model}

A Structural Equation Model (SEM) is a multivariate statistical technique that has emerged as a synthesis of path analysis, factor analysis and maximum-likelihood analysis. In SEM, there is a set of a priori specifications on which predictor variables are assumed to affect other variables, the directionalities of these effects are formulated, and these effects are tested with data. Additionally, An SEM can partition direct and indirect effects that one variable may have on another and estimate the strengths of these multiple effects. Thus, it is useful for exploring the complex networks of relationships found in natural ecosystems. An SEM was used to estimate the water environmental factors influencing the seasonal variations of fish trophic levels in this study. The abiotic variables included in these models were water temperature $(\mathrm{T})$ and total phosphorus $(\mathrm{TP})$; plankton components were phytoplankton (PP) and zooplankton (ZP). The goodness of fit of the model was tested by the Chi-square test [37]. The non-significant Chi-square test indicated that the model can be accepted. Four indexes were used to determine the goodness of fit of model: Root Mean Square Error of Approximation (RMSEA) and Standardized Root Mean Square Residual (SRMR) less than 0.05. Path coefficient estimates were obtained using the maximum-likelihood estimation technique; they are the equivalent of standardized partial regression coefficients and are interpreted as relative effects of one variable on another. Comparative Fit Index (CFI) was higher than 0.90 [38]. SEM analyses were performed with the "lavaan" package (http://lavaan.ugent.be/tutorial/index.html) in RStudio (version 1.1.414.0).

\subsection{Statistical Analyses}

Bayesian mixing models were used to estimate the contributions of the two types of food resources (phytoplankton and zooplankton), which were implemented in the SIAR package (Stable Isotope Analysis in RStudio) [39]. The difference analysis of trophic levels between bighead carp and silver carp was based on a t-test. One-way ANOVA was used to check the seasonal difference of zooplankton in the dietary compositions of the two fish species. Further, correlations between trophic levels of the 
two carp species and density of plankton and water parameters were tested with Pearson's correlation analyses. Last, a SEM was used to find the key indicators of seasonal variations affecting trophic levels of fish. All graphs were drasn using Origion Software, and statistical analyses were conducted with SPSS software (version 20.0). The correlation was expressed by the $p$ value, and a statistically significant value was considered at $p<0.05$.

\section{Result}

\subsection{The Seasonal Variations of Trophic Patterns of Filter-Feeding Fishes, Water Parameters and Densities of Plankton}

\subsubsection{The Seasonal Variations of Trophic Patterns of Silver Carp and Bighead Carp}

The trophic level of bighead carp was significantly higher than that of silver carp $(t=2.283$, $p=0.033$, and their seasonal variations were obvious. The annual mean of bighead carp trophic level was $2.81 \pm 0.25$, in which the changes were not obvious in 4 months from January to April, but increased obviously in May (3.08 \pm 0.07$)$, then decreased, and reached the maximum in September $(3.25 \pm 0.06)$ and October $(3.28 \pm 0.08)$. The annual mean trophic level of silver carp was $2.51 \pm 0.34$, which was similar to the trend of the bighead carp trophic level, and its trophic levels in May (2.88 $\pm 0.15)$, September $(3.21 \pm 0.11)$ and October $(3.03 \pm 0.13)$ were obviously higher than other months (Figure $2 \mathrm{~A}$ ). $\delta^{13} \mathrm{C}$ of silver carp ranged from -28.31 to $16.79 \%$ and $\delta^{15} \mathrm{~N}$ from 8.23 to $15.20 \%$; $\delta^{13} \mathrm{C}$ of bighead carp ranged from -33.99 to $-22.08 \%$ ond $\delta^{15} \mathrm{~N}$ from 6.68 to $14.66 \%$ (Figure 2). Standard ellipse areas (SEAC) based on $\delta^{13} \mathrm{C}$ and $\delta^{15} \mathrm{~N}$ values of bighead carp and silver carp showed clear resource partitioning in winter (Figure 2B) and summer (Figure 2D) but some isotopic niche overlaps in spring (Figure 2C) and autumn (Figure 2E). Trophic niche width was generally larger in spring and autumn than in summer and winter for both fish species (Figure 2F).

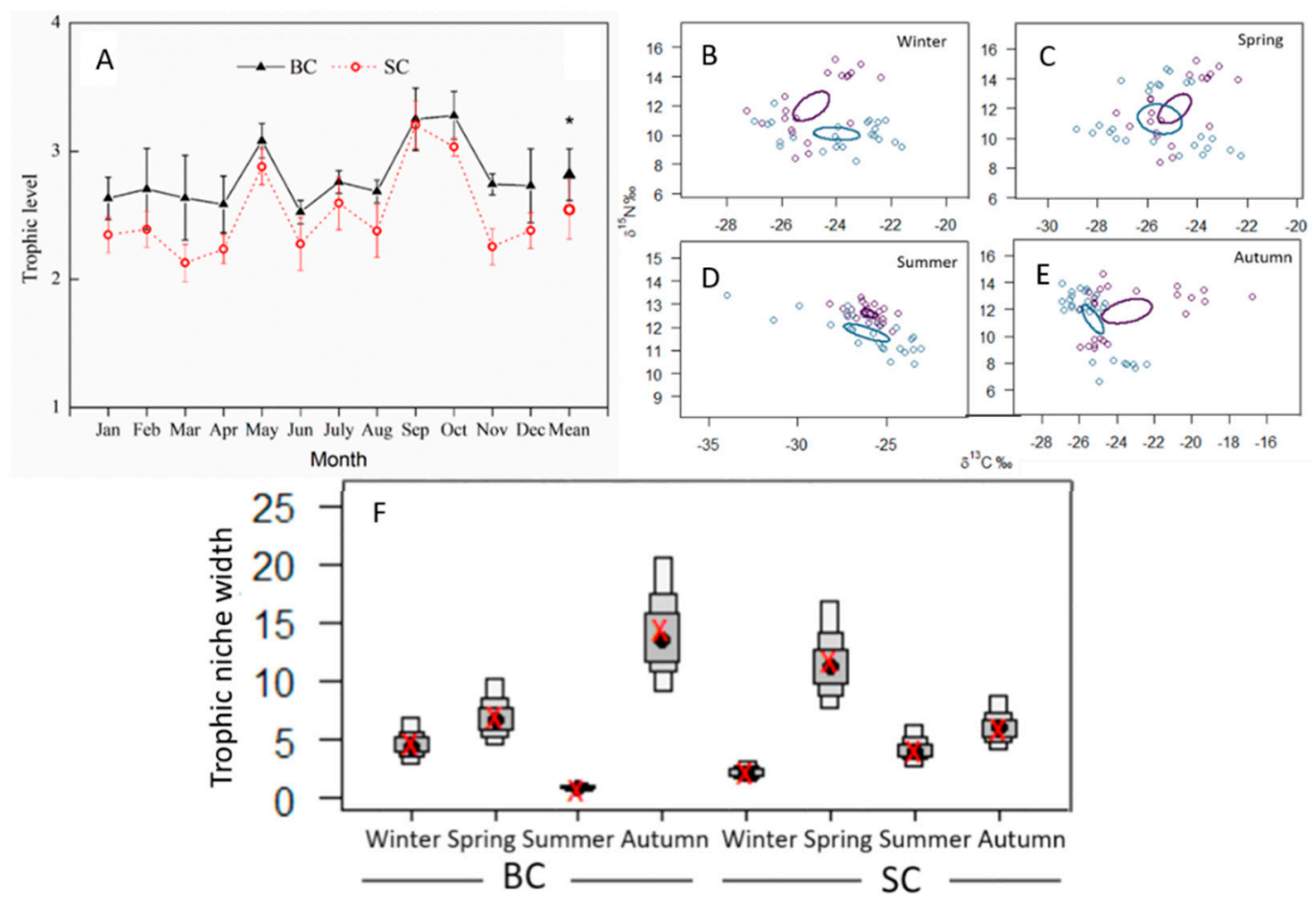

Figure 2. Seasonal variations of trophic patterns of silver carp (SC) and bighead carp (BC). Asterisks denote significance at the $p<0.05$ level. (A) is the trophic level of two fish species. (B-E) indicate isotopic niche width marked with the standard ellipse area corrected for small sample sizes (SEAC) for bighead carp (purple empty circles) and silver carp (blue empty circles) in winter, spring, summer and autumn, respectively. (F) represents the trophic niche width of the two fish species in different seasons. 


\subsubsection{Seasonal Variations of Abiotic and Biological Parameters}

The seasonal variations of the density of plankton during the study are presented in Figure 3. The densities of phytoplankton were low from January to April in 2017, mainly due to the reduction in cyanophyta which was the abundant phylum in other seasons. The first peak of the density of phytoplankton occurred in May, decreased in June and then rose slowly in September reaching the maximum (Figure 3A), and the density of cyanophyta constituted $85.12 \%$ of the total phytoplankton density. Regarding seasonal variations in zooplankton density, the minimum occurred in March, and then it showed an obvious increase in May, followed by a decrease from June to August and an increase to the maximum in September. The density of copepoda was higher than that of cladocera at most times, except in March and September (Figure 3B). Clear seasonal variations in water temperature were observed, with the highest values $\left(>38^{\circ} \mathrm{C}\right)$ occurring from August to September in 2017. TN was low in the 4 months from January to April, and reached the maximum in May (mean: $1.32 \pm 0.20 \mathrm{mg} / \mathrm{L}$ ), and then decreased. The peak in TP, $0.018 \pm 0.006 \mathrm{mg} / \mathrm{L}$, occurred in July, but the TP was lower in the other months (Figure 3C).
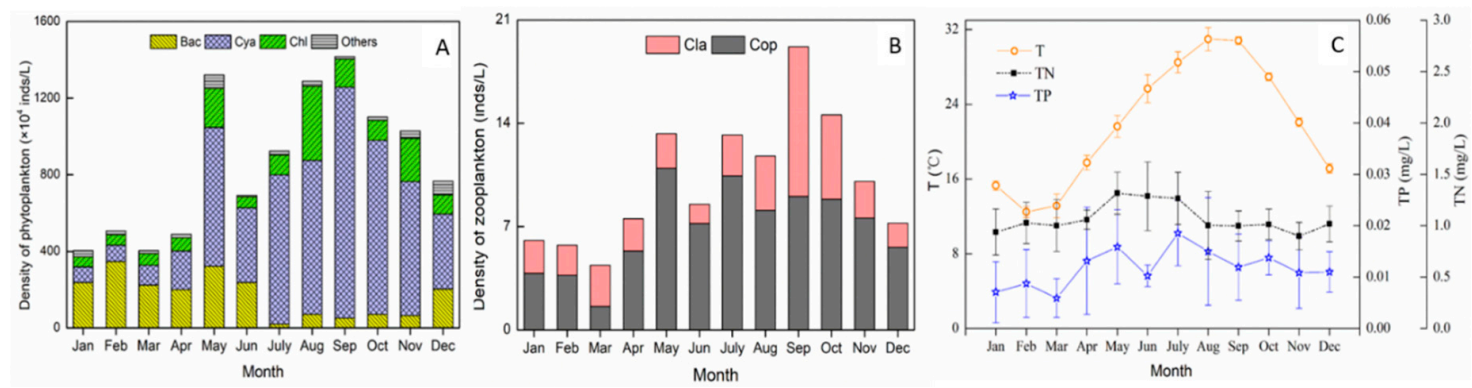

Figure 3. Seasonal variations of water parameters and densities of plankton. T, TN and TP represent water temperature, total nitrogen and total phosphorus, respectively. Bac, Cya, Chl, Cop and Cla represent bacillariophyta, chlorophyta, cyanophyta, copepoda and cladocera, respectively, in plankton.

\subsection{Dietary Compositions of Silver Carp and Bighead Carp Based on Gut Contents and Stable Isotopic Analysis}

Relatively wet weight percentages of gut contents in the two fish species are shown in Figure 4. The results showed that bighead carp used zooplankton as the main food source; the annual average wet weight percentage of zooplankton is $89.46 \%$, and the annual average wet weight percentage of zooplankton and phytoplankton was $66.75 \%$ and $33.25 \%$, respectively, in silver carp. According to the seasonal changes of the dietary habit of silver carp and bighead carp, zooplankton was the main food resource for bighead carp, and zooplankton and phytoplankton were the major resources for silver carp. Zooplankton, especially cladocera, was the absolute dominant food resource in the whole year for both carps, except for silver carp in winter. Both bighead carp and silver carp consumed more zooplankton in spring and autumn than in winter and summer (Table 1).

Table 1. Seasonal difference of zooplankton in dietary compositions of the two fish species.

\begin{tabular}{cccccc}
\hline & \multicolumn{5}{c}{ Bighead Carp } \\
\hline & Season & Winter & Spring & Summer & Autumn \\
\hline \multirow{3}{*}{ Silver carp } & Winter & 1 & $<\mathbf{0 . 0 0 1} * *$ & 0.179 & $\mathbf{0 . 0 0 2} * *$ \\
& Spring & $<\mathbf{0 . 0 0 1} * *$ & 1 & $\mathbf{0 . 0 0 2} * *$ & 0.208 \\
& Summer & $\mathbf{0 . 0 0 3} * *$ & $0.042^{*}$ & 1 & $\mathbf{0 . 0 3 0}$ \\
& Autumn & $<\mathbf{0 . 0 0 1} * *$ & 0.886 & $\mathbf{0 . 0 1 6}{ }^{*}$ & 1 \\
\hline
\end{tabular}

Note: Upper right corner represents bighead carp, and bottom left in italics represents silver carp. Significant effects are indicated in bold. Asterisks denote highly significant, with $p<0.01\left(^{* *}\right)$ and significance, with $0.01<p<0.05\left(^{*}\right)$. 


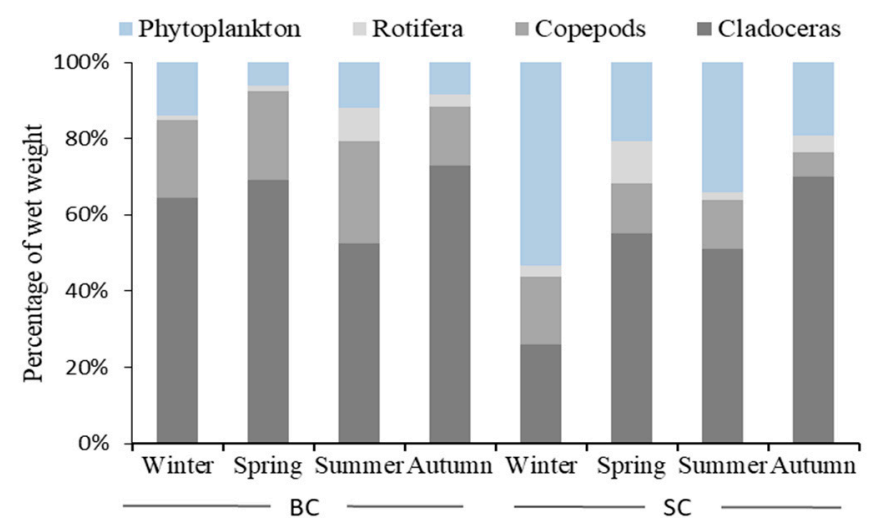

Figure 4. Seasonal variations of dietary compositions in gut contents of silver carp (SC) and bighead $\operatorname{carp}(\mathrm{BC})$.

Contribution proportions of zooplankton for bighead carp were higher than phytoplankton in the whole year, spatially in spring $(67.29 \pm 23.71)$ and autumn $(73.57 \pm 11.47)$. Phytoplankton and zooplankton played the same important roles for silver carp, with the annual contribution proportions of phytoplankton and zooplankton were $45.03 \%$ and $54.97 \%$, respectively. Contribution proportions of zooplankton were higher in spring $(62.48 \pm 20.52 \%)$ and autumn $(67.05 \pm 5.20 \%)$ than in winter $(47.32 \pm 7.78 \%)$ and summer $(43.01 \pm 3.51 \%)$ (Table 2$)$.

Table 2. Contribution proportions of food resources in phytoplankton (PP) and zooplankton (ZP) base on stable isotopic analysis.

\begin{tabular}{cccccc}
\hline \multirow{2}{*}{ Fish Species } & \multirow{2}{*}{ Food Resource } & \multicolumn{4}{c}{ Contribution Proportions (\%) } \\
\cline { 3 - 6 } & & Winter & Spring & Summer & Autumn \\
\hline \multirow{2}{*}{ Bighead carp } & PP & $42.07 \pm 2.92$ & $32.71 \pm 23.71$ & $47.88 \pm 2.21$ & $26.42 \pm 11.47$ \\
& ZP & $57.93 \pm 2.92$ & $67.29 \pm 23.71$ & $52.11 \pm 2.21$ & $73.57 \pm 11.47$ \\
\hline \multirow{2}{*}{ Silver carp } & PP & $52.68 \pm 7.78$ & $37.52 \pm 20.52$ & $56.98 \pm 3.51$ & $32.95 \pm 5.20$ \\
& ZP & $47.32 \pm 7.78$ & $62.48 \pm 20.52$ & $43.01 \pm 3.51$ & $67.05 \pm 5.20$ \\
\hline
\end{tabular}

\subsection{The Factors Affecting the Seasonal Variation of Trophic Levels of Fish}

Pearson's correlation coefficient method showed that the densities of phytoplankton, cyanophyta, zooplankton and cladocera might be important factors influencing the seasonal variations of trophic level of silver carp and bighead carp. The densities of phytoplankton and zooplankton were significantly positively related to the trophic level of silver carp $(p=0.014$ and $p=0.001)$ and bighead carp $(p=0.013$ and $p=0.003$ ). The densities of cyanophyta and cladocera showed extremely significant positive correlations with the trophic levels of silver carp $(p=0.003$ and $p=0.002)$ and bighead carp $(p=0.005$ and $p=0.006$ ) (Table 2). There were positive correlations between zooplankton and phytoplankton, and both phytoplankton and zooplankton showed significant positive correlations with $\mathrm{T}(p=0.001$ and $p<0.001)$ and TP $(p=0.021$ and $p=0.019)$ (Table 3 ).

The interaction between water environments and the trophic levels of the filter-feeding fish in freshwater ecosystem is complicated. To further explore water environmental influences on the trophic levels of the filter-feeding fish, 4 variables were measured, including total phosphorus, water temperature, density of phytoplankton and density of zooplankton. This study constructed the SEM based on a temporal scale to analyze the underlying factors influencing the seasonal variations of fish trophic levels. The fit for model for silver carp showed a $\chi^{2}$-test statistic value of 2.577 with $3 d f$ and a $p$-value of 0.462; the value of RMSEA was $<0.001$, and CFI was 1.000 . The model for bighead carp showed a $\chi^{2}$-test statistic value of 1.864 with $3 d f$ and $p$-value of 0.601 ; the value of RMSEA was $<0.001$, and CFI was 1.000. SEM showed that TP (standardized path coefficient $=0.485, p=0.004$ ) and water 
temperature (standardized path coefficient $=0.470, p=0.006$ ) directly affected phytoplankton, and phytoplankton significantly affected zooplankton (standardized path coefficient $=0.793, p<0.001$ ), but the standardized direct effects of phytoplankton were negative on silver carp, and 0.006 on bighead carp. Results also showed that the zooplankton exerted a direct and dominant positive effect on the trophic level of silver carp (standardized path coefficient $=0.765, p=0.049$ ) and bighead carp (standardized path coefficient $=0.916, p=0.002$ ) (Figure 5). The dominant influence of zooplankton was supported by Pearson's correlation analyses (Table 3). These results indicated that the trophic level of bighead carp and silver carp likely varied with the density of zooplankton, but water environment and phytoplankton were drivers of seasonal variation of zooplankton.

Table 3. Correlations between trophic patterns of fish and water environments in Lake Qiandao.

\begin{tabular}{lccccc}
\hline & \multicolumn{2}{c}{ Trophic Level } & \multicolumn{2}{c}{ Density of Plankton } \\
\hline \multirow{2}{*}{$\begin{array}{l}\text { Density of } \\
\text { phytoplankton }\end{array}$} & BC & 0.356 & 0.413 & 0.088 & $\mathbf{0 . 0 3 3} 3^{*}$ \\
& Cya & $0.005^{* *}$ & $0.003^{* *}$ & $<0.001^{* *}$ & $<0.001^{* *}$ \\
& Chl & 0.654 & 0.784 & $0.008^{* *}$ & 0.174 \\
Density of & PP & $0.013^{*}$ & $0.014^{*}$ & 1 & $<0.001^{* *}$ \\
zooplankton & Cop & 0.064 & 0.051 & $<0.01^{* *}$ & $<0.001^{* *}$ \\
& Cla & $0.006^{* *}$ & $0.002^{* *}$ & $0.038^{*}$ & $0.002^{* *}$ \\
Water & ZP & $0.003^{*}$ & $0.001^{* *}$ & $<0.001^{* *}$ & 1 \\
parameters & TP & 0.296 & 0.238 & $0.021^{*}$ & $0.019^{*}$ \\
& TN & 0.919 & 0.614 & 0.609 & 0.539 \\
& T & 0.184 & 0.118 & $0.001^{* *}$ & $<0.001^{* *}$ \\
\hline
\end{tabular}

Note: BC, SC, ZP and PP represent bighead carp, silver carp, zooplankton and phytoplankton, respectively. Bac, Cya, Chl, Cop and Cla represent bacillariophyta, chlorophyta, cyanophyta, copepoda and cladocera, respectively, in plankton. Asterisks denote highly significant, with $p<0.01(* *)$ and significant, with $0.01<p<0.05\left(^{*}\right)$.

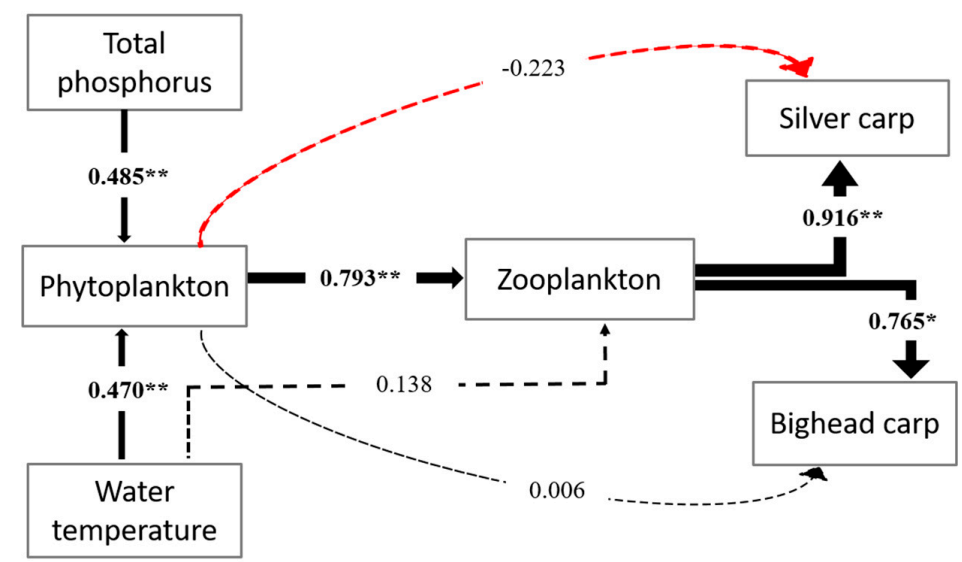

Figure 5. Path diagram of the SEM based on the interaction between environmental variables (total phosphorus, water temperature, density of phytoplankton and density of zooplankton) and trophic levels of the filter-feeding fish (bighead carp and silver carp). Boxes represent observed variables; directions of the arrows go from independent to dependent variables; numbers on the arrows correspond to the standardized path coefficients, and the relative strength of a relationship is indicated by arrow thickness and the standardized path coefficient. Significant and non-significant path coefficients are indicated by full and dotted lines, respectively; black and red arrows indicate positive and negative flows of causality $(p<0.05)$, respectively. The model involves two independent variables (bighead carp and silver carp) and four dependent variables (total phosphorus, water temperature, density of phytoplankton, and density of zooplankton). Significant effects were denoted in bold, and asterisks indicate highly significant, with $\left.p<0.01{ }^{* *}\right)$ and significant, with $0.01<p<0.05\left(^{*}\right)$. 


\section{Discussion}

\subsection{Seasonal Trophic Patterns of the Bighead Carp and Silver Carp}

Previous studies have found that the trends of seasonal variation of trophic levels of fishes were not associated with their body size or ages, but might be explained by other ecological factors, such as the water environment or flexible foraging strategies [12]. In this study, we found that trophic levels of the filter-feeding fish followed the seasonality of resource availability. Combined stable isotopic analysis and dietary analysis revealed that the filter-feeding fish tended to have higher trophic levels in spring and autumn because of the higher densities of food resources (zooplankton and phytoplankton). Furthermore, in seasons with abundant food resources, foraging strategies also result in a higher trophic level, i.e., the increased consumption ratio of zooplankton. Importantly, high seasonal variations of food resource distribution led to a heterogeneous habitat in different seasons, which could explain the changes of seasonal diet patterns and trophic level of filer-feeding fish observed in the present work.

This study speculated that the seasonal variations of food resources, especially density of zooplankton (cladocera), could indicate the dynamic change of trophic levels of the filter-feeding fish. The key reasons that caused fish trophic level changes could be considered based on the following: Firstly, Pearson correlation analysis and SEM showed that TP (standard path coefficient $=0.485$, $p<0.001$ ) and temperature (standard path coefficient $=0.470, p<0.001$ ) directly affected the density of phytoplankton. Therefore, nutrient and temperature affected the density and distribution of primary food sources, and then indirectly altered the trophic structure of consumers in complex seasonal trophic interaction. Secondly, our results showed that seasonal variations of phytoplankton significantly influenced the density of zooplankton (standard path coefficient $=0.793, p<0.001$ ), suggesting that phytoplankton was an important food sources for zooplankton. The highest peak of zooplankton density occurred in September (Figure 3), and showed positive correlations with trophic levels of two fishes. This might reflect that temporal variations in density of food resources transferred to higher trophic levels of consumers via the food chain [22]. Thirdly, under conditions of rich food resources, flexible dietary strategies were applied by fish to adapt to the seasonal changes of food resources [5]. In our study, gut contents and Bayesian mixing model showed that in comparison with phytoplankton, much more zooplankton (especially cladocera) was consumed by the two carps in Spring and Autumn (Figures 4 and 5). Optimal foraging theory predicted that fish would actively choose the more profitable detectable preys to maximize energetic benefits eliminating costs of handling and searching [40,41]. Bigheaded carps can find the regions of high zooplankton abundance by epibranchial organs [42]. Silver carp may filter all the zooplankton individuals and most phytoplankton individuals, while bighead carp is not efficient with respect to phytoplankton. Therefore, the dietary composition of bighead carp has a higher proportion of zooplankton and thus a higher trophic level [2,8]. Although the density of cladocera was less than that of copepoda in the lake for most of the time, cladocera was the optimal food for two carps due to the weak escape ability. Hence, the percentage of cladocera in gut contents was greater than that of copepoda. Because zooplankton had a direct effect on the trophic levels of the filter-feeding fish as SEM showed, cladocera could be the most important direct factor to influence the seasonal variations of trophic levels of the filter-feeding fish.

Differences in trophic levels between bighead carp and silver carp along the whole year were also found in this study. Although both bighead carp and silver carp utilize planktonic resources (zooplankton and phytoplankton), they can coexist by regulating their trophic levels and feeding [8]. Based on stable isotope analysis, there were dietary overlaps between silver carp and bighead carp and the trophic niche width was obviously larger for both fish species in spring and autumn (with abundant available resources). Previous studies showed that under more availability of resources, the trophic niche width would be correspondingly broader [8]. Combined Bayesian mixing model and identification of gut contents revealed that the contributions of zooplankton to the diets of bighead carp were higher than for silver carp. That is why the trophic level of bighead carp was always significantly higher than that of silver carp in changes with the season. Xu and Xie (2004) constructed the food web 
structure of Lake Donghu and showed that the contribution proportion of zooplankton for bighead carp (74\%) was higher than that of silver carp (54\%). Song (2013) examined temporal dynamics in food resource utilization by two carp species in our study region. Our results are in agreement with a previous study constructed in Lake Donghu and Lake Qiandao [43,44], showing that bighead carp consumed more zooplankton throughout the year.

\subsection{The Effects of Bottom-Up and Top-Down Control on Trophic Levels of Filter-Feeding Fish}

Abundant filter-feeding fish often play a key role in freshwater ecosystem, as links between plankton and top consumers [8]. Evidence about bottom-up ecosystem regulation indicates that water environment-driven changes in plankton communities can influence top consumers and potential fishery sources through the dynamics of key mid-trophic-level fish [45,46]. Indeed, most of these studies have assumed explicitly or implicitly that water environments affect fish indirectly through their food resources; this assumption in itself implies that bottom-up control is important. Our result showed that seasonal variation of total phosphorus and water temperature could indirectly affect trophic level of fish, by mediating the abundance of phytoplankton and zooplankton directly and indirectly along the food chain. According to these findings, the seasonal variation of water environment could be an important indicator for the temporal dynamics of the food web trophic pattern in freshwater ecosystems.

The magnitude of seasonal variations of trophic level reported here reflects the intensity of top-down effects (e.g., by altering the foraging strategies) that have potentially important consequences for the food web structure, as well as individual growth. For example, a dietary ratio for bighead carp shift from eating $73.57 \%$ zooplankton and $26.43 \%$ phytoplankton to eating $57.93 \%$ zooplankton and $42.07 \%$ phytoplankton (i.e., a reduction in trophic level of $\sim 1.77$ ) would likely change the strength of species interactions in food web as well as the activity costs and growth of individual fish [47]. Such temporally dynamic foraging strategies were considered important for the "dynamic stability" [48] of complex freshwater ecosystems [49]. In addition, flexible and diverse trophic interactions can play a key role in sustaining material circulation and energy flow in freshwater ecosystems. Regardless, seasonal shifts in trophic level are not the unique to freshwater ecosystems, but research about how trophic level response to seasonality of the water environment could be crucial for food web stability.

\section{Conclusions}

We found that the trophic levels of silver carp and bighead carp showed significant seasonal fluctuations. Specifically, the filter-feeding fish generally had a high trophic level when the food resources were abundant. Results indicated that seasonal variation of water environments (total phosphorus and water temperature) could affect the primary producers, which influenced the trophic patterns of filter-feeding fish directly and indirectly through bottom-up control. Therefore, the seasonal variations of water environments could be an important indicator for the temporal dynamics of trophic pattern in freshwater ecosystems. Furthermore, the magnitude of seasonal variations of trophic levels could reflect the intensity of top-down effects (e.g., by altering the foraging strategies) that have potentially important consequences for the food web structure. Our research about trophic level response to seasonality of the water environment is of crucial significance for food web stability.

Author Contributions: P.X., C.J., J.X. and J.Y. conceived, designed and manage the work plan; J.Y. wrote the paper; Z.Y., Z.W., J.R.L., L.W. and Y.W. collected the samples and sample measurements. X.D. and H.S. modified this manuscript. All authors made contributions to this work.

Acknowledgments: This work was supported by the research on fishery development mode regulation and fishery management scheme based on water environmental safety in Qiandao Lake (CACGZF[2016]22), the National Natural Science Foundation of China (Grant No. 31700400), the State Key Laboratory of Freshwater Ecology and Biotechnology (Grant No. 2019FBZ03) and the National Natural Science Foundations of China (Grant No. 31872687). We also thank the anonymous reviewers for providing valuable comments on the manuscript.

Conflicts of Interest: The authors declare no conflict of interest. 


\section{References}

1. Elton, C. Animal Ecology; Macmillan: New York, NY, USA, 1927.

2. Zhou, Q.; Xie, P.; Xu, J.; Ke, Z.X.; Guo, L.G.; Cao, T. Seasonal variations in stable isotope ratios of two biomanipulation fishes and seston in a large pen culture in hypereutrophic Meiliang Bay, Lake Taihu. Ecol. Eng. 2009, 35, 1603-1609. [CrossRef]

3. Hampton, S.E.; Galloway, A.W.; Powers, S.M.; Ozersky, T.; Woo, K.H.; Batt, R.D.; Labou, S.G.; O’Reilly, C.M.; Sharma, S.; Lottig, N.R. Ecology under lake ice. Ecol. Lett. 2017, 20, 98-111. [CrossRef] [PubMed]

4. McMeans, B.C.; McCann, K.S.; Humphries, M.; Rooney, N.; Fisk, A.T. Food Web Structure in Temporally-Forced Ecosystems. Trends Ecol. Evol. 2015, 30, 662-672. [CrossRef] [PubMed]

5. Sha, Y.C.; Su, G.H.; Zhang, P.Y.; Zhang, H.; Xu, J. Diverse dietary strategy of lake anchovy Coilia ectenes taihuensis in lakes with different trophic status. J. Ichthyol. 2015, 55, 866-873. [CrossRef]

6. Kondoh, M. Foraging Adaptation and the Relationship Between Food-Web Complexity and Stability. Science 2003, 299, 1388-1391. [CrossRef] [PubMed]

7. McCann, K.S.; Rasmussen, J.B.; Umbanhowar, J. The dynamics of spatially coupled food webs. Ecol. Lett. 2005, 8, 513-523. [CrossRef]

8. Yao, X.; Huang, G.; Xie, P.; Xu, J. Trophic niche differences between coexisting omnivores silver carp and bighead carp in a pelagic food web. Ecol. Res. 2016, 31, 831-839. [CrossRef]

9. Vander Zanden, M.J.; Shuter, B.J.; Lester, N.P.; Rasmussen, J.B. Within- and among-population variation in the trophic position of a pelagic predator, lake trout (Salvelinus namaycush). Can. J. Fish. Aquat. Sci. 2000, 57, 725-731. [CrossRef]

10. Post, D.M.; Takimoto, G. Proximate structural mechanisms for variation in food-chain length. Oikos 2007, 116, 775-782. [CrossRef]

11. Tunney, T.D.; McCann, K.S.; Lester, N.P.; Shuter, B.J. Food web expansion and contraction in response to changing environmental conditions. Nat. Commun. 2012, 3, 1105. [CrossRef]

12. Yu, J.; Guo, L.G.; Zhang, H.; Xu, J.; Hu, H.M.; Xue, T.; Luo, C.Q.; Yi, C.L.; Hu, Y.F.; De Silva, K.; et al. Spatial Variation in Trophic Structure of Dominant Fish Species in Lake Dongting, China during Dry Season. Water 2018, 10, 602. [CrossRef]

13. Akin, S.; Winemiller, K.O. Seasonal variation in food web composition and structure in a temperate tidal estuary. Estuaries Coasts 2006, 29, 552-567. [CrossRef]

14. Zhou, Q.; Xie, P.; Xu, J.; Ke, Z.; Guo, L. Growth and food availability of silver and bighead carps: Evidence from stable isotope and gut content analysis. Aquac. Res. 2009, 40, 1616-1625. [CrossRef]

15. Ruiz-Cooley, R.I.; Gerrodette, T.; Fiedler, P.C.; Chivers, S.J.; Danil, K.; Ballance, L.T. Temporal variation in pelagic food chain length in response to environmental change. Sci. Adv. 2017, 3, e1701140. [CrossRef]

16. Hellmann, C.; Wissel, B.; Winkelmann, C. Omnivores as seasonally important predators in a stream food web. Freshw. Sci. 2013, 32, 548-562. [CrossRef]

17. Nakano, S.; Murakami, M. Reciprocal subsidies: Dynamic interdependence between terrestrial and aquatic food webs. Proc. Natl. Acad. Sci. USA 2001, 98, 166-170. [CrossRef]

18. Soykan, C.U.; Sabo, J.L. Spatiotemporal food web dynamics along a desert riparian-upland transition. Ecography 2009, 32, 354-368. [CrossRef]

19. Xie, P. Gut contents of silver carp, Hypophthalmichthys molitrix, and the disruption of a centric diatom, Cyclotella, on passage through the esophagus and intestine. Aquaculture 1999, 180, 295-305. [CrossRef]

20. Yi, C.; Guo, L.; Ni, L.; Luo, C. Silver carp exhibited an enhanced ability of biomanipulation to control cyanobacteria bloom compared to bighead carp in hypereutrophic Lake Taihu mesocosms. Ecol. Eng. 2016, 89, 7-13. [CrossRef]

21. Li, Y.; Xie, P.; Zhang, J.; Tao, M.; Deng, X. Effects of filter-feeding planktivorous fish and cyanobacteria on structuring the zooplankton community in the eastern plain lakes of China. Ecol. Eng. 2017, 99, 238-245. [CrossRef]

22. McMeans, B.C.; Kadoya, T.; Pool, T.K.; Holtgrieve, G.W.; Lek, S.; Kong, H.; Winemiller, K.; Elliott, V.; Rooney, N.; Laffaille, P.; et al. Consumer trophic positions respond variably to seasonally fluctuating environments. Ecology 2019, 100, e02570. [CrossRef]

23. Post, D.M. Using stable isotopes to estimate trophic position: Models, methods, and assumptions. Ecology 2002, 83, 703-718. [CrossRef] 
24. Xu, J.; Zhang, H.; Cai, Y.; García Molinos, J.; Zhang, M. Optimal response to habitat linkage of local fish diversity and mean trophic level. Limnol. Oceanogr. 2016, 61, 1438-1448. [CrossRef]

25. Xie, P.; Liu, J. Practical success of biomanipulation using filter-feeding Fish to control cyanobacteria blooms: A synthesis of decades of research and application in a subtropical hypereutrophic lake. Sci. World J. 2001, 1, 337-356. [CrossRef]

26. Zhou, Y.; Zhang, Y.; Jeppesen, E.; Murphy, K.R.; Shi, K.; Liu, M.; Liu, X.; Zhu, G. Inflow rate-driven changes in the composition and dynamics of chromophoric dissolved organic matter in a large drinking water lake. Water Res. 2016, 100, 211-221. [CrossRef]

27. Zhai, X.Y.; Zhang, Y.Y.; Wang, X.L.; Xia, J.; Liang, T. Non-point source pollution modelling using Soil and Water Assessment Tool and its parameter sensitivity analysis in Xin'anjiang catchment, China. Hydrol. Process 2014, 28, 1627-1640. [CrossRef]

28. Sooknah, R.D.; Wilkie, A.C.J.E.E. Nutrient removal by floating aquatic macrophytes cultured in anaerobically digested flushed dairy manure wastewater. Ecol. Eng. 2004, 22, 27-42. [CrossRef]

29. Yu, J.L.; Liu, Z.W.; He, H.; Zhen, W.; Guan, B.H.; Chen, F.Z.; Li, K.Y.; Zhong, P.; Teixeira-de Mello, F.; Jeppesen, E. Submerged macrophytes facilitate dominance of omnivorous fish in a subtropical shallow lake: Implications for lake restoration. Hydrobiologia 2016, 775, 97-107. [CrossRef]

30. Wedchaparn, O.; Zhao, L.; Fan, Y.; He, D.; Zhang, H.; Ivan, L.N.; Liu, Q.; Ayisi, C.L. Comparison of the trophic niches between two planktivorous fishes in two large lakes using stable isotope analysis. Biochem. Syst. Ecol. 2016, 68, 148-155. [CrossRef]

31. Huang, X.; Chen, W.; Cai, Q. Survey, Observation and Analysis of Lake Ecology; Standard Methods for Observation and Analysis in Chinese Ecosystem Research Network, Series V.; Standards Press of China: Beijing, China, 1999.

32. Vitál, Z.; Specziár, A.; Mozsár, A.; Takács, P.; Boros, G. Applicability of gill raker filtrates and foregut contents in the diet assessment of filter-feeding Asian carps. Fundam. Appl. Limnol. 2015, 187, 79-86. [CrossRef]

33. Xie, P. Gut contents of bighead carp (Aristichthys nobilis) and the processing and digestion of algal cells in the alimentary canal. Aquaculture 2001, 195, 149-161. [CrossRef]

34. O'Reilly, C.M.; Hecky, R.E.; Cohen, A.S.; Plisnier, P.D. Interpreting stable isotopes in food webs: Recognizing the role of time averaging at different trophic levels. Limnol. Oceanogr. 2002, 47, 306-309. [CrossRef]

35. Xu, J.; Wen, Z.; Gong, Z.; Zhang, M.; Xie, P.; Hansson, L.A. Seasonal Trophic Niche Shift and Cascading Effect of a Generalist Predator Fish. PLoS ONE 2012, 7, e49691. [CrossRef] [PubMed]

36. Jackson, A.L.; Inger, R.; Parnell, A.C.; Bearhop, S. Comparing isotopic niche widths among and within communities: SIBER - Stable Isotope Bayesian Ellipses in R. J. Anim. Ecol. 2011, 80, 595-602. [CrossRef] [PubMed]

37. Bollen, K.A.; Stine, R.A. Bootstrapping Goodness-of-Fit Measures in Structural Equation Models. Sociol. Methods Res. 1992, 21, 205-229. [CrossRef]

38. Arbuckle, J.L. IBM SPSS Amos 20 User's Guide; IBM Corp: New York, NY, USA, 2011.

39. Parnell, A.C.; Inger, R.; Bearhop, S.; Jackson, A.L. Source partitioning using stable isotopes: Coping with too much variation. PLoS ONE 2010, 5, e9672. [CrossRef] [PubMed]

40. Macarthur, R.H.; Pianka, E.R. On optimal use of patchy environment. Am. Nat. 1966, 100, 603-609. [CrossRef]

41. Svanback, R.; Bolnick, D.I. Intraspecific competition affects the strength of individual specialization: An optimal diet theory method. Evol. Ecol. Res. 2005, 7, 993-1012.

42. Hansen, A.; Ghosal, R.; Caprio, J.; Claus, A.W.; Sorensen, P.W. Anatomical and physiological studies of bigheaded carps demonstrate that the epibranchial organ functions as a pharyngeal taste organ. J. Exp. Biol 2014, 217, 3945-3954. [CrossRef]

43. Xu, J.; Xie, P. Studies on the Food Web Structure of Lake Donghu Using Stable Carbon and Nitrogen Isotope Ratios. J. Freshw. Ecol. 2004, 19, 645-650. [CrossRef]

44. Song, G. Feeding Habits of Silver Carp and Bighead Carp in Qiandaohu Lake; Shanghai Ocean University: Shanghai, China, 2013.

45. Beaugrand, G.; Brander, K.M.; Lindley, J.A.; Souissi, S.; Reid, P.C. Plankton effect on cod recruitment in the North Sea. Nature 2003, 426, 661-664. [CrossRef] [PubMed]

46. Matsuzaki, S.S.; Suzuki, K.; Kadoya, T.; Nakagawa, M.; Takamura, N. Bottom-up linkages between primary production, zooplankton, and fish in a shallow, hypereutrophic lake. Ecology 2018, 99, 2025-2036. [CrossRef] [PubMed] 
47. Sherwood, G.D.; Pazzia, I.; Moeser, A.; Hontela, A.; Rasmussen, J.B. Shifting gears: Enzymatic evidence for the energetic advantage of switching diet in wild-living fish. Can. J. Fish. Aquat. Sci. 2002, 59, 229-241. [CrossRef]

48. Leigh, C.; Burford, M.A.; Sheldon, F.; Bunn, S.E. Dynamic stability in dry season food webs within tropical floodplain rivers. Mar. Freshw. Res. 2010, 61, 357-368. [CrossRef]

49. Pettit, N.E.; Naiman, R.J.; Warfe, D.M.; Jardine, T.D.; Douglas, M.M.; Bunn, S.E.; Davies, P.M. Productivity and Connectivity in Tropical Riverscapes of Northern Australia: Ecological Insights for Management. Ecosystems 2017, 20, 492-514. [CrossRef]

(C) 2019 by the authors. Licensee MDPI, Basel, Switzerland. This article is an open access article distributed under the terms and conditions of the Creative Commons Attribution (CC BY) license (http://creativecommons.org/licenses/by/4.0/). 